\title{
Дезинфекция скорлупы растворами полигексаметиленгуанидин хлорида и ее влияние на ветеринарно-санитарные показатели пищевых яиц
}

Козак С.С., главный научный сотрудник, доктор биологических наук, профессор

Всероссийский научно-исследовательский институт птицеперерабатывающей промышленности (ВНИИПП) - филиал ФНЦ «ВНИТИП» РАН

\begin{abstract}
Аннотащия: Яйца и яйцепродукты могут быть причиной отравлений из-за загрязнения патогенными микроорганизмами. Для побышения микробиологической безопасности сбежих куриных яии и яйцепродуктов, используемых для питания, необходимо обеззаражибать скорлупу пищебых яиц. Приведены результаты исследований дезинфииирующих свойств средства на основе полигексаметиленгуанидин хлорида (ПМГХ) и ветеринарно-санитарной оценки куриных пищебых яии после дезинфекиии скорлупы. Дезинфииирующие сбойства ПМГХ изучали согласно «Методам лабораторных исследований и испытаний дезинфекиионных средсть для оценки их эффектибности и безопасности». Микробиологические, фризико-химические и органолептические показатели яии, определяли по стандартным методикам. Установили, что применение для дезинфекции 0,4\% раствора ПМГХ при экспозиции 2 и 5 мин обеспечивает инактивацию Salmonella typhimurium на поверхности скорлупы и не влияет на ветеринарно-санитарные показатели яиц. Яйца после дезинфекции 6 течение 15 суток хранения при $4 \pm 20^{\circ} \mathrm{C}$ соответствовали требованиям ГОСТ на яйца куриные пищебые.
\end{abstract}

Ключебые слова: дезинфекиия, полигексаметиленгуанидин хлорид, скорлупа, качество яиц.

Введение. Яйцо и яйцепродукты являются полноценными пищевыми продуктами, занимающими достойное место в питании человека. В то же время, множественные тоскикоинфекции сальмонеллезной этиологии из-за контаминации патогенами яиц все еще встречаются в развитых странах, хотя профилактические методы осуществляются в соответствии с сертифицированными национальными стандартами. Заболеваемость людей сальмонеллезом возросла во всем мире и продолжает оставаться важной проблемой общественного здравоохранения [1].

Яйца и продукты из них, такие как десерты, кондитерские изделия, смеси для выпечки, майонез и многие полуфабрикаты, могут быть причастны к вспышкам пищевых отравлений из-за контами- нации патогенными микроорганизмами [2].

Salmonella enterica серовариантов typhimurium (S. typhimurium) и enteritidis (S. enteritidis) является основной и преобладающей причиной пищевого сальмонеллеза вследствие контаминации яиц на фермах. Общепризнанно, что загрязненная скорлупа является одним из основных путей заражения человека сальмонеллами, вызывая болезни пищевого происхождения [1]. В связи с этим существует вероятность загрязнения производимых яйцепродуктов патогенной микрофлорой, способной вызывать пищевые отравления [1,3].

Сальмонеллы обладают сравнительно высокой устойчивостью к воздействию внешних факторов и хорошо сохраняются в молоке, мясе, на поверхности и внутри яиц и т.д.; так, они сохраняют жизнеспособность на скорлупе яиц до 3 месяцев, в яичном порошке - до 9 месяцев [4].

Имеется целый ряд исследований по влиянию радиационной обработки на качество и безопасность яичных продуктов. В Российской Федерации такая обработка запрещена [5-7].

В настоящее время в России яичный порошок, содержащий сальмонеллы, обеззараживают путем его прогревания в специальных камерах при температуре $60 \pm 1^{\circ} \mathrm{C}$ в течение 7-10 суток в упаковках (крафт-мешках) [8]. Очевидно, что такой способ обеззараживания очень энергозатратный и требует специальных условий для его осуществления. Поэтому производители, для предупреждения попадания условно-патогенной и 
патогенной микрофлоры в жидкие и сухие яичные продукты, подвергают скорлупу яиц, направляемых на производство этих продуктов, санитарной обработке. Так как мойка яиц не обеспечивает полного удаления микробных контаминантов с поверхности скорлупы [9,10], для выпуска безопасных яйцепродуктов проводят дезинфекцию скорлупы [11].

Для этих целей предложен ряд химических и физических способов, но, несмотря на это, поиск эффективных способ дезинфекции поверхности скорлупы пищевых яиц продолжается. На рынке дезинфицирующих средств, наряду с другими, представлены средства на основе полигексаметиленгуанидин хлорида (ПМГХ), которые обладают широким спектром антимикробной активности в отношении как Грам-отрицательных, так и Грам-положительных бактерий. Эти средства не обладают сенсибилизирующим действием, по параметрам острой токсичности относятся к 3-му классу умеренно опасных веществ при введении в желудок и к 4-му классу малоопасных веществ при нанесении на кожу. ПМГХ применяют для дезинфекции поверхностей, оборудования, уборочного инвентаря и др. в лечебно-профилактических, детских учреждениях и на предприятиях общепита.

Целью настоящей работы являлось исследование возможности использования средства на основе ПМГХ для дезинфекции скорлупы, а также изучение влияния такой обработки на ветеринарно-санитарные показатели пищевых яиц, что представляет интерес для ветеринарной науки и практики.

Материал и методика исследований. Исследования про- водили в лаборатории санитарно-гигиенической оценки сырья и продуктов ВНИИПП.

При выполнении работы исследовали дезинфицирующие свойства средства на основе ПМГХ - «Биопаг-Д» (БД), представляющего собой 20\% водный раствор ПМГХ, прозрачную жидкость от бесцветного до желтого цвета, pH раствора 7,0-9,5.

Дезинфицирующую активность БД изучали в опытах с тест-объектами из батистовой ткани, контаминированной тест-культурами S. typhimurium штамм 55 (ST) согласно методике [12]. Растворы БД готовили на стерильной воде в день опыта в концентрациях от 0,05 до 0,5\% по действующему веществу (ДВ) из расчета 0,5 мл раствора на каждый тест-объект.

В рабочие растворы БД погружали батистовые тест-объекты, контаминированные ST. По истечении заданной экспозиции вынимали по 2 тест-объекта, и после 2-кратной промывки в воде (по 5 мин) делали посев на мясо-пептонный бульон. Посевы помещали в термостат при температуре $37^{\circ} \mathrm{C}$. Учет результатов проводили ежедневно в течение 7 дней. Окончательное суждение о наличии у испытуемого вещества бактерицидных свойств делали после обобщения результатов 3 повторных опытов.

Для изучения дезинфицирующей эффективности БД в лабораторных условиях проводили контаминацию скорлупы пищевых яиц ST. Бактериальную взвесь готовили из суточной агаровой культуры. Предварительно яйца механически очищали щетками, промывали водопроводной водой, затем фламбировали и погружали во взвесь, содержащую ST. После контаминации яйца обсушивали при комнатной температуре и погружали в испытуемые растворы БД на 2 и 5 мин.

Рабочие растворы БД готовили на стерильной водопроводной воде в день опыта. Началом опыта считали момент смачивания яиц. Контролем служили яйца, не подвергавшиеся действию средства БД после их погружения в емкость со стерильной водопроводной водой на время, равное экспозиции для опытных яиц. После заданной экспозиции яйца извлекали из растворов БД и опускали в емкость со стерильной водопроводной водой. Через 5 мин их переносили во вторую емкость со стерильной водопроводной водой.

Для отбора проб со скорлупы яиц использовали метод ополаскивания [8]. Микробиологические, физико-химические и органолептические показатели яиц определяли по стандартным методикам [13,14].

Результаты исследований и их обсуждение. В начале исследований изучили дезинфицирующую активность средства БД с использованием стерильных батистовых тест-объектов, контаминированных ST. Результаты исследований представлены в табл. 1. Установлено, что инактивацию ST в опытах с батистовыми тест-объектами обеспечивал 0,4\% раствор средства БД при экспозиции 2 и 5 мин.

Для изучения дезинфицирующей эффективности средства БД предварительно провели экспериментальное загрязнение поверхности скорлупы яиц ST. Контаминацию скорлупы проводили бактериальной взвесью ST (вариант 1) и смесью бактериальная взвесь + куриный помет + белок куриного яйца (вариант 2, имитирующий реальные условия контаминации яиц на птицефабрике). Данные по количеству ST на поверхности скорлупы конта- 
минированных яиц представлены в табл. 2.

Далее яйца с экспериментально загрязненной ST скорлупой использовали для изучения дезинфицирующей эффективности растворов БД. Дезинфекцию скорлупы яиц проводили методом погружения, результаты представлены в табл. 3. Инактивация ST на поверхности скорлупы яиц после ее контаминации по обоим вариантам и в этом случае обеспечивалась $0,4 \%$ раствором БД при экспозиции 2 и 5 мин.

В дальнейших исследованиях изучали влияние дезинфекции скорлупы средством БД на микробиологические показатели содержимого яиц, изменение массы и рН белка в процессе хранения. Для этого контрольную партию яиц не дезинфицировали и не мыли водой, а скорлупу яиц опытных групп дезинфицировали 0,4\% раствором БД при экспозиции 2 и 5 мин. По истечении заданной экспозиции яйца споласкивали стерильной водой, обсушивали при комнатной температуре и хранили при $4 \pm 2^{\circ} \mathrm{C}$ в бытовом холодильнике в течение 15 суток. Исследование яиц проводили на 5, 10 и 15 сутки хранения.

Установлено, что через 15 суток хранения потеря массы яиц в контрольной группе составила

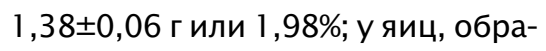
ботанных 0,4\% раствором БД при

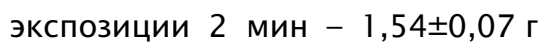
или 2,14\%; у яиц, обработанных

\begin{tabular}{cccccccc}
\hline Tаблица 1. Дезинфицирующая активность средства БД (n=10) \\
\hline \multirow{2}{*}{$\begin{array}{c}\text { Экспозиция, } \\
\text { мин }\end{array}$} & \multirow{7}{*}{ Рост тест-культуры ST } \\
\cline { 2 - 8 } & Контроль & \multicolumn{7}{c}{ Концентрация раствора, \% (по ДВ) } \\
\cline { 2 - 8 } & & $\mathbf{0 , 0 5}$ & $\mathbf{0 , 1}$ & $\mathbf{0 , 2}$ & $\mathbf{0 , 3}$ & $\mathbf{0 , 4}$ & $\mathbf{0 , 5}$ \\
\hline 2 & + & + & + & \pm & \pm & - & - \\
\hline 5 & + & + & + & \pm & \pm & - & - \\
\hline
\end{tabular}

Примечание: (+) - наличие роста микроорганизмов; (-) - отсутствие их роста; ( \pm ) - непостоянный эффект.

Таблица 2. Количество ST на поверхности скорлупы после контаминации

\begin{tabular}{|c|c|c|}
\hline \multirow{2}{*}{$\begin{array}{c}\text { Вариант контаминации скорлупы } \\
\text { яиц }\end{array}$} & \multicolumn{2}{|c|}{ Количество ST, КОЕ/(см² $(\mathrm{M} \pm \mathrm{m})$} \\
\hline & В исходной суспензии & $\begin{array}{l}\text { На поверхности } \\
\text { скорлупы }\end{array}$ \\
\hline Вариант 1 (В1) & $(2,03 \pm 0,09) \times 10^{9}$ & $(2,42 \pm 0,11) \times 10^{5}$ \\
\hline Вариант 2 (В2) & $(2,11 \pm 0,1) \times 10^{9}$ & $(2,54 \pm 0,12) \times 10^{4}$ \\
\hline
\end{tabular}

0,4\% раствором средства БД при

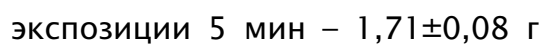
или 2,28\%.

При закладке яиц на хранение рН их белка составлял 6,06士0,19. Через 15 суток этот показатель в контрольной группе увеличился до $6,25 \pm 0,26$, а в опытных - до

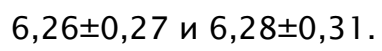

При микробиологических исследованиях сальмонеллы и бактерии группы кишечной палочки в содержимом яйца не были выделены ни в одном случае. Количество мезофильных аэробных и факультативно-анаэробных микроорганизмов (КМАФАнМ) в содержимом яиц всех групп при их закладке и после 15 суток хранения не превышало 10 KOE/г.

Качественные характеристики яиц после их хранения в течение 15 суток, как в контрольной группе, так и в опытных, соответствовали требованиям ГОСТ 31654-
2012: скорлупа яиц оставалась чистой, без изменений цвета, неповрежденной; воздушная камера была неподвижной или отмечалась ее незначительная подвижность, высота не превышала 7 мм; белок оставался плотным, светлым, прозрачным, желток прочным, малозаметным, и лишь y некоторых яиц наблюдалось небольшое его отклонение от центра яйца.

Были проведены производственные испытаниямя средства БД для дезинфекции поверхности скорлупы пищевых яиц. Перед началом испытаний отобрали смывы с поверхности скорлупы 30 яиц (контроль) до проведения санитарной обработки.

При механизированном способе санитарной обработки яйца, после выгрузки на транспортер агрегата, овоскопировали. Затем яйца мыли в течение 2 мин на

\begin{tabular}{|c|c|c|c|c|c|c|c|}
\hline \multirow{3}{*}{$\begin{array}{c}\text { Вариант контаминации } \\
\text { скорлупы яиц }\end{array}$} & \multirow{3}{*}{ Экспозиция (мин) } & \multicolumn{6}{|c|}{ Наличие роста тест-культуры } \\
\hline & & \multirow{2}{*}{ Контроль } & \multicolumn{5}{|c|}{ Концентрация раствора, \% (по ДВ) } \\
\hline & & & 0,2 & 0,3 & 0,4 & 0,5 & 1,0 \\
\hline \multirow{2}{*}{ B1 } & 2 & + & + & + & - & - & - \\
\hline & 5 & + & + & \pm & - & - & - \\
\hline \multirow{2}{*}{ B2 } & 2 & + & + & + & - & - & - \\
\hline & 5 & + & + & \pm & - & - & - \\
\hline
\end{tabular}

Примечание: (+) - наличие роста микроорганизмов; (-) - отсутствие их роста; (士) - непостоянный эффект. 
роликовом транспортере в камере мойки (скорлупа механически очищалась специальными щетками и смачивалась раствором моющего средства с температурой $\left.38 \pm 2^{\circ} \mathrm{C}\right)$, ополаскивали водой 10 с, дезинфицировали и повторно ополаскивали водой. Растворы наносили методом погружения и орошения в момент вращения их по горизонтальной оси в машине для санитарной обработки яиц. При дезинфекции механизированным способом рабочие растворы использовали многократно (до появления видимого загрязнения) с восстановлением необходимой концентрации средства БД.

При дезинфекции ручным способом яиц с наличием загрязнений на скорлупе помещали на решетки в ванны в пластмассовых прокладках для замачивания в растворе моющего средства с температурой $28 \pm 2^{\circ} \mathrm{C}$ на 10 мин. Затем скорлупу очищали щетками, промывали водой с температурой $18 \pm 2{ }^{\circ} \mathrm{C}$ и дезинфицировали путем погружения яиц в ванну на 5 мин в растворы БД комнатной температуры (растворы использовали однократно). Яйца с визуально чистой скорлупой дезинфицировали, минуя этап мойки. После дезинфекции яйца ополаскивали в течение $10 \mathrm{c.}$

Установили, что при механизированном способе дезинфекции использование 0,4\% раствора БД при экспозиции 2 мин обеспечивает снижение КМАФАнМ до $6,03 \pm 0,27 \times 10 \mathrm{KOE} / \mathrm{cm}^{2}$ и инактивацию БГКП. При дезинфекции ручным способом использование 0,4\% раствора БД при экспозиции 5 мин обеспечивает инактивацию БГКП и снижение КМАФАнМ до $<10 \mathrm{KOE} / \mathrm{cm}^{2}$. При механизированном и ручном способах де- зинфекции растворами БД структура скорлупы и подскорлупной оболочки, окраска скорлупы яиц не изменялись.

Заключение. Применение при санитарной обработке скорлупы пищевых яиц 0,4\% (по ДВ) раствора средства БД на основе ПМГХ при механизированном (экспозиция 2 мин) и ручном (экспозиции 5 мин) способах дезинфекции обеспечивает инактивацию ST на ее поверхности и не влияет на ветеринарно-санитарные показатели яиц.

Яйца, обработанные средством БД, в течение 15 суток хранения при $4 \pm 2{ }^{\circ} \mathrm{C}$ соответствуют требованиям ГОСТ на яйца куриные пищевые.

\section{Исследование Выполнено $\mathcal{G}$} рамках госзадания № АAАAA20-120010690002-3.

\section{Литература}

1. Ahmed W. Effect of spraying hatching eggs by different levels of vinegar on embryological development, hatchability and physiological performance of dandarwi chicks / Ahmed W., Abdelfattah M.G., Abdelnabi M. // Egypt. Poult. Sci. J. - 2019. - V. 39, No 1. - P. 291-309.

2. Al-Bachir M. Improvement of microbiological quality of hen egg powder using gamma irradiation // Intl. J. Food Stud. - 2020. - V. 9. - P. 75-83.

3. Braden C.R. Salmonella enterica serotype Enteritidis and eggs: a national epidemic in the United States // Clin. Infect. Dis. - 2006. - V. 43, No 4. - P. 512-517.

4. Сальмонеллез сельскохозяйственных животных и птиц: характеристика возбудителя, распространенность в Пермском крае и эпидемиологическое значение / чугунова Е.О., Татарникова Н.А. - Пермь: ИПЦ «Прокрость», 2014. - 134 с.

5. Козак С.С. Научное обоснование обеспечения микробиологической безопасности продукции птицеводства: автореферат дис. ... д-ра биол. наук. - Москва, 2013. - 47 с.

6. Narvaiz P. Physicochemical and sensory analyses on egg powder irradiated to inactivate Salmonella and reduce microbial load / Narvaiz P., Lescano G., Kairiyama E. // J. Food Saf. - 1992. V. 12, No 4. - P. 263-282.

7. Aydin T. Detection and original dose assessment of egg powders subjected to gamma irradiation by using ESR technique // Rad. Phys. Chem. - 2015. V. 114 . - P. 43-49.

8. Инструкция о мероприятиях по снижению микробной обсемененности тушек птицы, скорлупы яиц, продуктов из мяса птицы и яиц и деконтаминации их от сальмонелл. - М., 1994. 9. Козак С.С. Средства на основе надкислот - эффективные дезинфектанты для птицепромышленности / Козак С.С., Догадова Н.Л., Городная Н.А. [и др.] // Птица и птицепродукты. 2020. - №4. - C. 45-47.

10. Hudson L.K. Alternative antimicrobial commercial egg washing procedures / Hudson L.K., Harrison M.A., Berrang M.E. [et al.] // J. Food Prot. 2016. - V. 79, No 7. - P. 1216-1220.

11. Козак С.С. Ветеринарно-санитарная оценка пищевых яиц после дезинфекции скорлупы средством на основе натриевой соли трихлоризоциануровой кислоты // Птица и птицепродукты. - 2021 . - №2. - С. 46-48.

12. Р 4.2.2643-10. Методы лабораторных исследований и испытаний дезинфекционных средств для оценки их эффективности и безопасности.

13. ГОСТ 32149-2013. Пищевые продукты переработки яиц сельскохозяйственной птицы. Методы микробиологического анализа.

14. ГОСТ 31654-2012. Межгосударственный стандарт. Яйца куриные пищевые. Технические условия.

\section{Для контакта с автором:}

Козак Сергей Степанович E-mail: vniippkozak@gmail.com 


\title{
Disinfection of Eggshell with the Solutions of Polyhexamethylene Guanidine Chloride and its Effects on the Sanitary Parameters of Table Eggs
}

\author{
Kozak S.S. \\ Federal Scientific Center "All-Russian Research and Technological Institute of Poultry" \\ of Russian Academy of Sciences
}

\begin{abstract}
Summary: Table eggs and egg derived products can be a cause of intoxications and alimentary diseases in consumers resulting from the contamination by pathogenic microbial species. The microbiological safety of eggs and egg products can be improved by the disinfection of the eggshells of freshly laid eggs. The disinfecting properties of the solutions of polyhexamethylene guanidine chloride (PHMG) with different concentrations (0.05$0.5 \%$ ) and sanitary parameters (microbiological, physiochemical, organoleptic) of eggs after the disinfection of eggshells with PHMG were studied according to a governmentally approved protocols. It was found that $0.4 \%$ solution of PHMG at exposures 2 and 5 min by immersion effectively inactivated Salmonella typhimurium after the experimental contaminations of eggshells and did not affect the sanitary parameters of the eggs. After the storage for 15 days at $4 \pm 20^{\circ} \mathrm{C}$ the disinfected eggs still complied with the requirements of governmental standards (COST) for the quality of table eggs.
\end{abstract}

Keywords: disinfection, polyhexamethylene guanidine chloride, eggshell, egg quality.

\section{ФНЦ «ВНИТИП» РАН}

\section{www.vnitip.ru Тел.: +7 (496) 549-95-75 E-mail: vnitip@vnitip.ru}

\section{внитиП Предлагает}

перспективные планы селекционно-племенной работы по совершенствованию продуктивных качеств

сельскохозяйственной птицы

новые среды для разбавления спермы самцов птицы

эфффективные рецепты комбикормов для сельскохозяйственной птицы

национальные и межгосударственные стандарты на продукцию птицеводства

прогрессивные ресурсосберегающие технологии промышленного производства яиц и мяса птицы

технологические проекты для птицефабрик

комплексные технологии переработки помета

\section{Проводит оценку}

новых видов кормов (в том числе нетрадиционных), комбикормов, биологического материала и продуктов птицеводства по показателям качества и безопасности

биологически активных веществ (ферментных препаратов, премиксов, пробиотиков и других добавок)

Дезинфицирующих средств

технологического оборудования для содержания птицы

\section{Оказывает консультативную помощь по вопросам}

кормления, содержания всех видов сельскохозяйственной птицы

технологии инкубации яиц и проведению биологи ческого контроля

селекционно-племенной работы в птицеводстве профилактики микотоксикозов
Проводит курсы повышения квалификации для специалистов птицеводческих хозяйств и преподавателей вузов 